\title{
Regulamentos da cultura: diversidade sexual e de gênero nos concursos juninos de Belém
}

\author{
Rafael da Silva Noleto' \\ 0000-0003-3140-5062 \\ Universidade Federal de Pelotas, Pelotas, RS, Brasil. 96.010-770 - ppgant@ufpel.edu.br
}

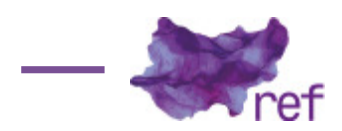

Resumo: Perscrutando os regulamentos que regem os concursos juninos promovidos como política pública pela Prefeitura Municipal de Belém e pelo Governo do Estado do Pará, procuro entender como esses documentos tentam gerir a intensa participação de homossexuais e pessoas trans nesses certames. O que dizem esses regulamentos? Quais são as formas implícitas e explícitas através das quais o Estado se refere à diversidade sexual e de gênero? Com essas perguntas em mente (e baseado em trabalho de campo realizado entre 2012 e 2016 nos concursos juninos de Belém), busco respondêlas a partir da análise desses documentos e dos discursos que se constroem em torno deles. Palavras-chave: gênero; sexualidade; São João; documentos; estado.

Regulations of Culture: Gender and Sexual Diversity in the Belém's June Contests

Abstract: Looking at the regulations guiding the June contests promoted as public policy by the municipal government of Belém and state government of Pará, I intend to understand how these documents try to manage the intense participation of homosexuals and transgender people in these events. What do these regulations say? What are the implicit and explicit ways in which the State refers to sexual and gender diversity? With these questions in mind (and based on field work done between 2012 and 2016 in the Belém's June competitions), I seek to answer them from the analysis of these documents and the discourses that are built around them.

Keywords: Gender; Sexuality; June festivals; Documents; State.

\section{O que (não) dizem os regulamentos}

Na busca pela compreensão de como 'gênero', 'raça' e 'sexualidade' se articulam, coreograficamente, nas performances de homossexuais e pessoas 'trans' nos concursos juninos de Belém (PA), observei que há um aparato discursivo para regular a produção de identidades de gênero e sexualidade nesse contexto. Ressalto que o presente artigo é decorrente de uma pesquisa de maior escopo que resultou em minha tese de doutorado (Rafael NOLETO, 2016). Embora nunca tenha sido um brincante de festas juninas, interessei-me pelo tema devido ao contato que tive com o universo da dança em Belém. Para entender as implicações políticas e estéticas dessa intensa participação de homossexuais e pessoas 'trans' no contexto performático das festas juninas, percebi a necessidade de aproximar três campos de investigação: estudos de gênero e sexualidade, pesquisas em cultura popular e antropologia da performance. ${ }^{\prime}$ Ao interpelar os regulamentos dos concursos oficiais das festas de São João em Belém, é possível entrever a ação do Estado na delimitação dos contornos que definem os significados do que seja cultura popular.

\footnotetext{
' A pesquisa foi iniciada em 2012, quando comecei a fazer trabalho de campo para elaboração de um projeto de pesquisa consistente, e se estendeu até 2016, quando defendi a tese de Doutorado. O presente trabalho foi realizado com apoio da Coordenação de Aperfeiçoamento de Pessoal de Nível Superior - Brasil (CAPES) - Código de Financiamento 001. Agradeço imensamente à CAPES pelo financiamento parcial da pesquisa entre os anos de 2013 e 2015. Após esse período, tornei-me professor efetivo no Magistério Superior e abdiquei do financiamento da pesquisa.
} 
Como um ente promotor de políticas públicas voltadas ao fomento e difusão das culturas populares, - Estado constrói um aparato discursivo que prescreve concepções normativas de 'tradição' e 'modernidade'. Tais concepções são, muitas vezes, conflitantes com o entendimento dos próprios agentes que, de fato, produzem as culturas populares, isto é, os brincantes e os dirigentes dos grupos que movimentam o calendário cultural das festas populares no Brasil.

No âmbito teórico, há um debate consolidado acerca dessas questões, muito influenciado, por exemplo, pelas ideias de Peter Burke (2010 [1978]), autor que se preocupou em perscrutar as tensas negociações entre 'tradição' e 'modernidade' no interminável processo dinâmico de reconstrução e ressignificação das culturas. Para Burke, os sujeitos possuem um grande poder de agência ao (re)criar, incessantemente, os gêneros expressivos que integram o conjunto de linguagens artísticas produzidas pelas culturas populares. Nesse caso, o poder de sanção para as inovações culturais em curso concentra-se nas mãos da comunidade de sujeitos que partilha dos mesmos códigos culturais dentro de uma organização social e política específica. É essa comunidade que legitima ou reprova as mudanças propostas por aqueles que, de fato, produzem o campo do simbólico.

Vale ressaltar que o trabalho de Peter Burke (2010 [1978]) problematiza, em termos históricos, a produção de uma ideia geral de "cultura popular", resultante das transformações políticas que desencadearam a expansão comercial da Europa por via da exploração de recursos humanos e naturais em escala global. Nesse contexto, compreendido entre os séculos XVI e XVII, a Europa vivenciou o fenômeno de intensos deslocamentos de populações rurais para áreas urbanas. A concentração de pessoas no tecido urbano ocasionou o fortalecimento do comércio interno nas metrópoles e favoreceu ainda a proliferação de manifestações artísticas populares (em suas mais variadas formas expressivas), trazidas por esses migrantes do contexto rural. A intensa circulação de materiais expressivos possibilitou o surgimento de um incipiente comércio do lazer, admitindo essas manifestações artísticas como importantes ao entretenimento das camadas baixas da população, além de movimentar certa economia da cultura. No que se refere à minha pesquisa, interesso-me pelas discussões de Burke na medida em que o autor fornece elementos importantes para se pensar os conceitos de "cultura popular", "tradição", "modernidade". Além disso, a especial atenção dada por Burke aos migrantes, que produzem cultura popular nas grandes metrópoles, é imprescindível para que se entenda, contemporaneamente, os grupos juninos que, em diversas capitais brasileiras, são compostos por muitos brincantes vindos dos interiores de seus respectivos estados. Na bibliografia brasileira, Luciana Chianca (2013) explora a relação entre festas juninas e migração.

Nesse sentido, a partir do que Eric Hobsbawm e Terence Ranger (2012 [1983]) nos fazem perceber, as tradições (e não apenas aquelas relativas ao campo da arte) são, historicamente, resultantes de processos oriundos da relação política entre grupos que necessitam afirmar, ritualmente, suas diferenças através de uma noção compartilhada de 'coesão'. Compreende-se que o cerne da discussão aqui presente é o próprio conceito de cultura através dos modos pelos quais as manifestações expressivas acabam se 'tradicionalizando'. No métier antropológico, o debate sobre o conceito de cultura é imenso. Discute-se desde a polissemia do termo às formas através das quais os antropólogos elaboram os dados etnográficos de suas pesquisas para, enfim, "inventar" a cultura. Outro grande debate é sobre a escrita etnográfica, isto é, o modo antropológico de registro de suas experiências em campo e das análises teóricas suscitadas por essas experiências. Esses debates estão presentes em Adam Kuper (2002), Roy Wagner (2012 [1975]), James Clifford (201 1 [1994]), Manuela Carneiro da Cunha (2009) e na coletânea organizada por James Clifford e George Marcus (2017 [1986]).

Considero que, no campo de pesquisa sobre culturas populares, a discussão sobre 'tradição' e 'modernidade' está devidamente contemplada em inúmeros trabalhos. No que se refere às festas juninas, autores como Eleonora Leal (2004), Elizabeth Lima (2010), Zulmira Nóbrega (2010), Chianca (2013), Eduardo Di Deus (2014), Hugo Menezes Neto (2015) e Elielton Gomes (2016) têm se debruçado sobre aspectos históricos, simbólicos, organizacionais e discursivos em torno das festas de São João nos mais diversos contextos. No meu caso, com base em trabalho de campo realizado entre 2012 e 2016 nos concursos juninos de Belém, pretendo problematizar um ponto específico e, muitas vezes, silenciado em investigações anteriores. Refiro-me ao protagonismo de homossexuais e pessoas 'trans' na composição das quadrilhas juninas que povoam os folguedos de São João, em Belém. Dentre os pesquisadores mencionados, apenas Di Deus (2014) concede certa atenção ao fato de que as quadrilhas juninas são espaços para construção de identidades sociais que falam acerca da diversidade sexual e de gênero.

Ressalto que utilizo a categoria 'trans', entre aspas, para me referir a identidades sexuais e de gênero diversas tais como travestis, transexuais e transgêneros. No âmbito socioantropológico, a bibliografia brasileira é repleta de pesquisas dedicadas à problematização dessas identidades 'trans' em diferentes contextos e sob diversos olhares. Não farei aqui uma problematização mais detalhada acerca dessas identidades, pois considero que esta discussão já foi contemplada em 
trabalhos tais como os de Marcos Benedetti (2005), Don Kulick (2008), Berenice Bento (2006; 2009; 2012), Bento; Larissa Pelúcio (2012), Jorge Leite Jr. (2011) e Anna Paula Vencato (2002; 2003; 2013). Assim, é importante salientar que estive atento aos processos através dos quais certos paradigmas de 'feminilidade' se inscrevem, coreograficamente, nos corpos de homossexuais e pessoas 'trans' inseridos no contexto de produção das festas juninas de Belém. A compreensão aqui empregada é signatária do que Judith Butler (2016) denomina como 'performatividade de gênero', isto é, um processo de 'assunção' dos sujeitos ao 'sexo' a partir da corporificação de normas regulatórias que materializam diferenciados graus de 'masculinidade' e 'feminilidade' nos corpos. Isso ocorre através da emergência do gênero nos corpos, que se dá a partir de um processo 'citacional' no qual os sujeitos 'citam' as normas regulatórias desde sua forma discursiva até a sua materialização como modos de apresentação de si. Abordei o conceito de performatividade de gênero em trabalhos anteriores nos quais exploro mais detidamente um diálogo com as proposições teóricas de Butler (2010; 2016). Basicamente, problematizei questões relativas à performatividade de gênero na relação entre fãs gays e cantoras da MPB (NOLETO, 2013) e, mais recentemente, discuti processos de produção de 'feminilidades' performativas no São João de Belém (NOLETO, 2018b).

No presente texto, minha atenção analítica está direcionada para a gestão discursiva da diversidade sexual e de gênero nos concursos de São João. Abordo particularmente os regulamentos que orientam os certames juninos de quadrilha e de miss, contemplando tanto os regulamentos dos concursos oficiais (promovidos e financiados pela Prefeitura Municipal de Belém e pelo Governo do Estado do Pará) quanto os regulamentos dos concursos realizados nos bairros "periféricos" de Belém (sob organização de produtores culturais e lideranças comunitárias). Diante da indubitável e importante presença de homossexuais e pessoas 'trans' no âmbito performático dos concursos juninos de Belém, meu foco de análise incide sobre como a diversidade sexual e de gênero é gerida de modo implícito ou explícito nesses regulamentos. Meu interesse reside em perscrutar não apenas o seu conteúdo textual, mas os discursos que se constroem em torno desses documentos através dos posicionamentos dos gestores culturais que os elaboram.

Para empreender minhas análises, foram consultados diversos regulamentos de certames e muitos outros documentos como, por exemplo, fichas de inscrição, releases de misses, reportagens de jornal, mapas de apresentações de quadrilhas e misses, manuais de jurados e outros materiais de divulgação dos concursos juninos como, por exemplo, os banners promocionais divulgados na internet e em aplicativos de comunicação. ${ }^{2} \mathrm{~A}$ consulta não se restringiu aos regulamentos dos certames de Belém, mas se expandiu para os regulamentos produzidos pela Confederação Brasileira de Entidades de Quadrilhas Juninas (CONFEBRAQ), que, em 2016, realizou em Belém o Concurso Nacional de Quadrilhas e o Concurso Nacional de Rainhas Juninas, eventos onde fiz trabalho de campo. Entendo que esses documentos podem fornecer informações relevantes sobre as formas discursivas de moldar práticas performáticas através do que esses documentos dizem explícita ou implicitamente. Mais do que tentar apreender o que esses documentos dizem sobre a diversidade sexual e de gênero, busquei perscrutar o poder revelador do silêncio dos regulamentos, observando suas entrelinhas e atentando para a força reguladora do que eles não dizem.

\section{Pares ou casais?}

No que se refere aos concursos juninos oficiais, há duas fundações culturais que atuam na realização desses eventos. Em âmbito municipal, os certames são promovidos pela Fundação Cultural do Município de Belém (FUMBEL). Em âmbito estadual, a realização dos concursos fica a cargo da Fundação Cultural do Estado do Pará (FCP/Centur). ${ }^{3}$ É no diálogo com essas fundações culturais, 'tradicionalmente' vinculadas ao fomento de ações voltadas à cultura popular da cidade, que surge emblemática e intensa batalha entre a travesti Raíssa Gorbatchof e a FUMBEL. Destaco que, apesar de já promover concursos de quadrilha antes do Governo do Estado, a Prefeitura de Belém só veio realizar o concurso 'Miss Caipira Gay' a partir do ano de 2001, quando houve uma polêmica, amplamente divulgada na imprensa local, envolvendo a travesti Raíssa Gorbatchof (vencedora do 'Miss Caipira Mix' de 2007). ${ }^{4}$ A querela foi documentada em reportagem de Suely Nascimento (2001) e dizia respeito a uma denúncia relativa à participação da travesti Raíssa Gorbatchof dançando como dama em uma quadrilha junina. Na reportagem, Raíssa advogava

\footnotetext{
${ }^{2}$ Tendo em vista que muitas das regras dispostas nesses regulamentos se repetem anualmente, fiz uma seleção dos principais trechos de interesse para este artigo. Contudo, é válido frisar que, para escrevê-lo, foram consultados diversos documentos emitidos pela FUMBEL, FCP, FCPTN, CONFEBRAQ e quadrilhas como Garra Junina e Sedução Ranchista entre os anos de 2012 e 2016. Os documentos que foram diretamente citados no artigo constam nas referências.

3 'Centur' é uma sigla utilizada para designar o Centro Cultural e Turístico Tancredo Neves, antigo nome da atual Fundação Cultural do Estado do Pará, criada na década de 1980. Até hoje os quadrilheiros ainda se referem à atual FCP como 'Centur', motivo pelo qual utilizo a sigla FCP/Centur.

${ }^{4}$ Miss Caipira Gay e Miss Caipira Mix são, respectivamente, concursos de miss realizados pela FUMBEL e FCP/Centur. Trata-se de certames voltados para homossexuais e pessoas 'trans'.
} 
em favor de que homossexuais e travestis pudessem desempenhar, coreograficamente, os papéis femininos nas apresentações das festas de São João em Belém.

Quando tive contato pessoal com Raíssa Gorbatchof, ela ressaltou que homossexuais e travestis sempre tiveram, historicamente, uma grande participação nos bastidores das festas juninas, alegando, dessa maneira, que a proibição da participação destes sujeitos nas quadrilhas era injusta. Em 2001, sob a pressão feita pelo então Movimento Homossexual de Belém (MHB), a comissão organizadora dos concursos de quadrilha promovidos pela FUMBEL permitiu a participação de homossexuais e pessoas 'trans' dançando como damas nos grupos, sem a penalização de desclassificar suas quadrilhas. Nesse mesmo período, a FUMBEL instituiu o concurso 'Miss Caipira Gay', que visava dar mais visibilidade à diversidade sexual e de gênero que é constitutiva do movimento junino de Belém. Esse debate foi muito representativo da possibilidade de diálogo mais progressista que o movimento homossexual da época teve com o poder executivo exercido pelo prefeito Edmilson Rodrigues (que era filiado ao PT e é hoje Deputado Federal pelo PSOL). Sendo assim, os regulamentos desses concursos passaram a utilizar a palavra par para designar as duplas de brincantes que integrarão as quadrilhas, sem fazer restrições relativas nem ao gênero nem à sexualidade dos participantes. O atual entendimento veiculado tanto pela FUMBEL quanto pela FCP/Centur é o de que as quadrilhas devem ser formadas por pares e não por casais, conforme os trechos do regulamento abaixo (replicados também no regulamento de 2016 emitido pela FCP/Centur):

Art. $8^{\circ}$ - A Quadrilha Junina deverá ser composta com o número de pares segundo sua categoria, a saber:

[...] II - A Quadrilha Junina ADULTA deverá ser composta com o número mínimo de 14 (quatorze) e máximo de 24 (vinte e quatro) pares e 01 (um) marcador (FUMBEL, 2014a).

O entendimento demonstrado pelos gestores culturais da FUMBEL e da FCP/Centur é o de permitir que os sujeitos ocupem em suas respectivas quadrilhas os cargos coreográficos que sejam condizentes com suas identidades sexuais e de gênero. No entanto, como certa vez afirmou Fafá Pinheiro (organizadora dos concursos juninos da FCP/Centur), a caracterização do par composto por um elemento 'masculino' e outro 'feminino' deve ser estritamente observada pelas quadrilhas. Ou seja, a díade estrutural cavalheiro/dama deve ser mantida sob pena de desclassificação dos grupos. Sugiro, portanto, que os certames juninos sustentam uma concepção normativa baseada na pressuposição da heterossexualidade e de um ideal de cisgeneridade dos sujeitos. Chamo esse processo de heterossexualidade e cisgeneridade coreográfica para designar uma narrativa dançada, não exatamente por intérpretes heterossexuais e cisgêneros, que é elaborada para criar efeitos performativos de heterossexualidade e cisgeneridade (NOLETO, $2017 ; 2018 b$ ). Assim, quando os regulamentos juninos admitem a adoção do termo pares em detrimento da expressão casais, produz-se um efeito performático de heterossexualidade e cisgeneridade que não é necessariamente representativo das verdadeiras identidades sexuais e de gênero dos brincantes em suas respectivas quadrilhas.

Acrescento que, em entrevista realizada com Tetê Oliveira, fundadora da Associação de Quadrilhas Juninas e Núcleo de Toadas do Estado do Pará (AQUANTO), perguntei sobre esse processo de mudança nos regulamentos, tão importante para a comunidade LGBT de Belém. Tetê concedeu um depoimento revelador de sua concepção heteronormativa - que faz emergir, ainda que involuntariamente, um discurso homo/transfóbico - acerca do que seria um casal. Em sua opinião, a ideia de casal é incompatível com possibilidades outras que estejam fora do âmbito da heterossexualidade e cisgeneridade. Sendo assim, quando a participação de pessoas LGBT nos concursos juninos de Belém foi discutida, no sentido de assegurar-lhes o direito de se constituir como brincantes em quaisquer postos coreográficos que mais se adequassem às suas respectivas identidades sexuais e de gênero, foi necessário haver, nos regulamentos, uma mudança pequena, mas muito significativa, em termos analíticos.

Ao substituir a palavra casal - anteriormente utilizada para designar as duplas de brincantes compostas por um homem e uma mulher cisgênero - pelo termo pares, criou-se a possibilidade de regulamentação definitiva da participação de homossexuais e pessoas 'trans' no conjunto de brincantes das quadrilhas. Se, por um lado, a mudança nos regulamentos representou um avanço para a integração da comunidade LGBT no contexto da cultura popular de Belém, por outro lado, a forma como essa integração foi feita subentende uma violência simbólica ao negar o status de casal às formações performáticas de duplas compostas por sujeitos políticos que não se encaixam nem nas divisões binárias de gênero nem no critério de serem protagonistas no campo da ideologia da heterossexualidade compulsória. Neste caso, tomo de empréstimo o provocativo termo 'heterossexualidade compulsória' de Adrienne Rich (2010).

Ressalto que esse não é um entendimento apenas local e regional. Pelo contrário, os regulamentos mais recentes dos concursos nacionais promovidos pela CONFEBRAQ também utilizam a nomenclatura pares a fim de designar as duplas de brincantes que performatizam identidades 
'masculinas' e 'femininas', evitando, dessa maneira, o termo casal. De acordo com o Parágrafo Único do Artigo $1^{\circ}$ do regulamento do concurso nacional de 2016,5 "A CONFEBRAQ reconhece como quadrilhas juninas os grupos de dança, formados em pares, que respeitem elementos básicos do ciclo junino no Brasil (CONFEBRAQ, 2016a)". Ainda falando sobre a sensível diferença semântica estabelecida entre os termos casal e pares, é necessário frisar que, recentemente, no regulamento do I Concurso Nacional de Noivos Juninos realizado pela CONFEBRAQ em 2015, foi sedimentado o entendimento de que um casal de noivos juninos só pode ser constituído com base na pressuposição da condição cisgênero dos brincantes para, então, assegurar a performance da heterossexualidade nos certames juninos. O regulamento é explícito quanto às prescrições destinadas aos possíveis brincantes que disputarão o título de melhor casal:

Art. $3^{\circ}$ - Somente poderão participar do I Concurso Nacional de Casais de Noivos Juninos, os casais de noivos juninos que atenderem aos seguintes requisitos:

I - Ser formado por um homem e uma mulher;

II - Ter nacionalidade brasileira;

III - Ser o casal de noivos juninos de um grupo ou quadrilha junina filiada à entidade estadual que for filiada à CONFEBRAQ;

IV - Ter até a data do Concurso a idade mínima de 16 anos, comprovados através de Carteira de Identidade ou Certidão de Nascimento (CONFEBRAQ, 2015b).

É importante destacar que há uma diferença entre os certames juninos de Belém (e grande parte do Pará) e os concursos de outros estados do Brasil: a inexistência ou não obrigatoriedade do casamento na apresentação das quadrilhas. Isso significa dizer que, enquanto em outros estados brasileiros as quadrilhas reservam, obrigatoriamente, um momento de destaque para a atuação de um casal de noivos na encenação de uma cerimônia de casamento, as quadrilhas de Belém prescindem da realização do casamento ou o tornam um momento facultativo da narrativa performática (NOLETO, 2017). Ao interpelar o regulamento elaborado pela CONFEBRAQ (2015b) para reger o I Concurso Nacional de Noivos Juninos, é possível encontrar de modo indubitável a exigência da condição cisgênero de ambos os brincantes que constituirão o casal de noivos. Por não se tratar de um simples par de brincantes, mas de um casal que protagonizará uma cena de casamento, a heterossexualidade é requerida e a condição cisgênero é evocada como um requisito de eliminação de possíveis candidatos ou candidatas que não cumpram tal determinação. Nesse caso, não há espaço de negociação para a heterossexualidade e cisgeneridade coreográfica. Deve-se assegurar que o casal de noivos seja realmente composto por brincantes cisgênero e, possivelmente, heterossexuais. Para além de ser um simples documento pessoal que possibilitaria a inscrição dos brincantes neste certame, atestando que suas idades estão em conformidade com as determinações do regulamento, considero que a exigência da carteira de identidade (ou da certidão de nascimento) é também uma importante aliada implícita no processo de aferição da cisgeneridade dos inscritos. ${ }^{6}$

Essa pressuposição de heterossexualidade e cisgeneridade é colocada de modo implícito no item 'do julgamento', presente no regulamento do I Concurso Nacional de Noivos Juninos. Constam no documento os seguintes critérios de avaliação:

Do Julgamento

Art. $9^{\circ}$ - A Comissão Julgadora avaliará os seguintes quesitos:

I - Desenvoltura - Expressão corporal, relação com o público, ocupação racional do espaço;

II - Sinergismo - Sintonia do casal, gestos e atitudes que denotem que o casal tem total interação;

III - Traje Típico / Figurino - Pertinência (qualidade, acabamentos, exageros, tipicidade junina) do traje, da maquilagem e penteado utilizados, bem como a relação com os adereços e figurino; IV - Coreografia - Plano coreográfico, sequência rítmica e criatividade;

$\mathrm{V}$ - Interpretação teatral - Modo como os casais incorporam os personagens de noivos juninos (CONFEBRAQ, 2015b [grifos meus]).

Destaco os incisos II e V, que estabelecem como critérios de avaliação os aspectos performáticos que se referem à interpretação cênica dos noivos. Esses critérios, denominados como 'sinergismo' e 'interpretação teatral', aludem ao potencial de convencimento cênico que o casal de noivos é capaz de demonstrar. A interação entre os brincantes é avaliada e a interpretação dos noivos deve convencer o público e os jurados de que eles realmente possuem uma relação afetiva. Aparentemente, esses critérios podem ser percebidos apenas como quesitos de julgamento da competência artística dos brincantes, mas, conhecendo o universo quadrilheiro, infiro que esse quesito também está relacionado a questões de gênero e sexualidade. Sugiro que os critérios de avaliação do sinergismo e da interpretação teatral dos noivos são estabelecidos para avaliar

\footnotetext{
${ }^{5}$ É possível verificar também o uso do termo pares (ao invés de casal) no regulamento do ano anterior (CONFEBRAQ, Regulamento do XI Concurso Nacional de Quadrilhas Juninas, 2015a).

${ }^{6}$ Aprofundarei mais adiante a problematização sobre a exigência da carteira de identidade no ato da inscrição nos certames.
} 
o nível de convencimento da relação heterossexual que esses personagens juninos performatizam em cena. Ou seja, a interação entre os polos 'masculino' e 'feminino' da coreografia deve transparecer que há, entre o casal de noivos, uma relação heterossexual convincente.

Tal compreensão foi confirmada etnograficamente quando, em junho de 2015 , fui convidado a ser jurado de um concurso junino em Tocantinópolis, cidade do interior do Tocantins e um dos mais importantes contextos de certames juninos desse Estado. Durante o curso de formação de jurados, Elpídio de Paula, membro da Federação de Quadrilhas Juninas do Tocantins (FEQUAJUTO), explicou os critérios de avaliação. Por ser considerado um especialista em certames juninos, fiquei como jurado do quesito 'conjunto', que avalia a totalidade da apresentação. Porém, dentre os diversos critérios, havia o quesito da interpretação dos brincantes, denominado na ocasião como 'verdade cênica' ou 'fé cênica'. Ao explicar sobre a interpretação dos brincantes, Fulano nos relatou exemplos de quando os quadrilheiros perdem o entusiasmo em cena e, consequentemente, prejudicam a avaliação da quadrilha no quesito 'interpretação'. Considerando o foco desse artigo, o exemplo mais significativo mobilizado por Fulano foi ao falar de situações em que 'os noivos são mais femininos do que as noivas' ou 'os noivos querem aparecer mais do que as noivas'. Esse tipo de ocorrência é frequente e prejudica os casais de noivos no que diz respeito à sua pontuação nos certames. Ou seja, a 'feminilidade' do noivo é um fator percebido como demonstrativo de sua suposta homossexualidade. Nesse caso, a desconfiança em torno da homossexualidade do noivo é o elemento impeditivo para que sua interpretação seja avaliada como ruim.

Em Belém, esse tipo de avaliação quanto à sexualidade e ao gênero dos brincantes está também materializado, por exemplo, nos manuais de jurados editados pela FUMBEL (2014c). É notável que, em documento consultado por mim, os gestores culturais da FUMBEL prescrevem alguns cuidados que os jurados devem ter ao escreverem suas justificativas de avaliação nos respectivos formulários avaliativos, que serão entregues posteriormente aos quadrilheiros. Nesse caso, é expressamente proibido o uso de alguns termos e expressões. De acordo com o documento, o jurado deve:

\footnotetext{
- Jamais utilizar termos subjetivos ou pessoais como: "gostei", "quase perfeito", "demonstrou um certo potencial", "acho mais ou menos", "beijos", "um forte abraço" etc. Ou ainda;

- Tratamentos como: queridos, amados, amigos...

- Comentários como: "não se aborreçam com este comentário", "me perdoem a crítica...", "Desculpem, amados, é construtivo, juro", "Entretanto, entendo a dificuldade do grupo", "Não irei tirar ponto, peço apenas que tome o devido cuidado quanto a isto, pois consiste em erro". - Expressões resumidas ou indefinidas como: "o quesito tal deu conta do seu trabalho", "apresentação satisfatória", "realizou apresentação com algumas técnicas", "dentro da regra" (para uma nota 10,0).

- Referências discriminativas, usando expressões como: trejeitos femininos, sexualidade etc. (FUMBEL, 2014c [grifos meus]).
}

Inseri todos esses pontos para que seja entendido o contexto mais amplo no qual a FUMBEL prescreve que o jurado não deve utilizar 'referências discriminativas' em suas justificativas por escrito. Como exemplo desse tipo de referência discriminatória, o Manual de Jurados destaca as expressões 'trejeitos femininos' e 'sexualidade'. Ao ler essas expressões é possível inferir que elas fazem referência ao julgamento quanto à interpretação da masculinidade performática dos cavalheiros. Como já dito, em Belém as quadrilhas não possuem obrigatoriamente um casal de noivos, por isso, a ênfase na avaliação da heterossexualidade e cisgeneridade coreográfica recai sobre os pares de brincantes. Nesse caso, a partir da análise das recomendações contidas no Manual de Jurados da FUMBEL, é possível notar que esta instituição entende como ofensiva a avaliação de que um determinado cavalheiro possui 'trejeitos femininos' e, por isso, não é convincente ao interpretar interações afetivas e sexuais direcionadas a uma dama.

A 'feminilidade' levanta a suspeita de homossexualidade e, portanto, é considerada como ofensa tanto ao trabalho de interpretação do brincante quanto à sua própria constituição social como sujeito generificado e sexualizado. A suposta homossexualidade não é apenas um simples dado acerca da variedade das expressões sexuais humanas, mas um elemento acusatório e degenerativo. Além disso, o Manual de Jurados da FUMBEL também considera como 'referência discriminativa' a palavra 'sexualidade', indicando que falar sobre sexualidade (ou seria sobre homossexualidade?) é também potencialmente ofensivo. Todo esse aparato discursivo em torno da heterossexualidade e cisgeneridade coreográfica é sintetizado no Manual de Jurados num item sobre a avaliação da coreografia. Dentre os diversos elementos coreográficos que devem ser analisados, os julgadores precisam avaliar 'o enamoramento dos brincantes como naturalidade de expressão' (FUMBEL, 2014c). Em resumo, os pares (e não casais) precisam apresentar-se como convincentemente enamorados, engajados numa relação heterossexual.

Menciono ainda que, a despeito de os concursos nacionais de quadrilha serem promovidos pela CONFEBRAQ há doze anos, somente em 2015 realizou-se um concurso voltado para avaliação do melhor casal de noivos juninos do Brasil. É interessante notar que, ainda em 2015, foi também 
realizado o I Concurso Nacional da Rainha Junina da Diversidade, voltado para candidaturas de homossexuais e pessoas 'trans' que almejam disputar o título nacional de Rainha Junina (CONFEBRAQ, 2015c). Essa proliferação de certames juninos indica um crescimento do movimento quadrilheiro por todo o Brasil e uma necessidade de valorizar, de modo mais particularizado, carreiras artísticas específicas dentro desse contexto performático como, por exemplo, os casais de noivos, as rainhas juninas e as rainhas juninas da diversidade. Em Belém, as rainhas são chamadas de misses e, ao invés de ser um cargo destinado a apenas uma única brincante (como a rainha), as misses possuem três categorias distintas nas quais podem disputar títulos juninos. Tratei dos concursos de miss em Belém em trabalhos anteriores (NOLETO, 2014; 2016; 2018a).

Ressalto que em todos os regulamentos consultados até o momento, seja em âmbito local, estadual ou nacional, existe certo esforço para que as diversas categorias de brincantes sejam frequentemente referidas, ainda que implicitamente, de modo a fixar suas identidades em termos de gênero. Nessa configuração, a figura do/da marcador/a de quadrilhas, personagem crucial para a performance de um grupo junino, é sempre mencionada no masculino nos textos dos regulamentos. Essa essencialização exclui outras possibilidades que verifiquei em campo. Por exemplo, a quadrilha Sedução Cabocla (do bairro do Tapanã, em Belém) possui uma marcadora travesti, Danna Moraes, que desafia a pressuposição de que, nas quadrilhas juninas, o cargo de marcador é sempre ocupado por homens cisgênero. Outro exemplo significativo, agora em âmbito nacional, foi quando constatei a presença de uma marcadora mulher (cisgênero) na quadrilha Origem Nordestina (Pernambuco), que disputou o XVI Concurso Nacional de Quadrilhas Juninas em Belém em 2016.

A partir desse processo criterioso de seleção, alteração e alternância situacional entre os termos que definem a atuação dos/das brincantes em seus respectivos grupos, atento para o fato de que não há neutralidade nos termos e designações utilizados nos documentos, pois todo e qualquer modo de designar opera duplamente, produzindo zonas legítimas e ilegítimas da existência política dos sujeitos. O exemplo mais emblemático mobilizado aqui consiste no fato de que a simples utilização do termo pares (ao invés de casais) carrega consigo uma ampla discussão sobre a digna incorporação da diversidade sexual e de gênero como parte constitutiva da quadra junina de Belém e dos contextos de produção de cultura popular em todo o Brasil. Assim, evitando fazer uma leitura superficial dos termos contidos nesses regulamentos, considero ser necessário problematizá-los, suspeitando de sua neutralidade e aleatoriedade.

Ainda que de modo não completamente adequado, certas alterações nos regulamentos juninos possibilitam o reconhecimento do direito à livre expressão das identidades de gênero e sexualidade no cerne da quadra junina de Belém. Assim, foram atendidas as demandas de todos aqueles sujeitos homossexuais, travestis e transexuais que desejavam desempenhar papéis coreográficos como damas. Do mesmo modo, abriu-se precedentes para que mulheres lésbicas (com performances de gênero masculinas) e homens transexuais pudessem ocupar os cargos de cavalheiros. Conforme a própria reportagem de Nascimento (2001) registrou, havia, na época, uma demanda de mulheres lésbicas para participarem dos certames como cavalheiros. No entanto, no trabalho de campo que empreendi entre 2012 e 2016, não encontrei nenhuma brincante assumidamente lésbica ou nenhum homem trans que, atualmente, esteja dançando como cavalheiro em alguma quadrilha.

Interpreto a não adesão massiva de lésbicas e homens trans aos certames juninos como um efeito reverso causado pela própria abertura dos regulamentos à diversidade sexual e de gênero. Explico: o fato de os regulamentos juninos agora permitirem que os sujeitos ocupem os cargos coreográficos que mais se adéquem às suas identidades sexuais e de gênero fez com que a homossexualidade masculina e as identidades 'trans' femininas se tradicionalizassem no centro performático da quadra junina de Belém. Isso favoreceu o estabelecimento de um consenso de que essas identidades sexuais e de gênero são dominantes nesse contexto, portanto, imprimem na quadra junina uma feminilidade exacerbada. Sendo assim, do ponto de vista de mulheres lésbicas masculinizadas e dos homens trans, sujeitos que constantemente reafirmam uma identificação com a expressão da masculinidade, os certames juninos deixam de ser atrativos. Ainda que os regulamentos permitam, oficialmente, a adesão de mulheres lésbicas masculinizadas e homens trans aos cargos de cavalheiros, ingressar em uma quadrilha significa, a partir dessa atual configuração do contexto junino, feminilizar-se, o que é estrategicamente indesejável para esses sujeitos políticos.

\section{Regulando misses e rainhas}

Adentrando ainda mais o debate sobre a regulação das identidades sexuais e de gênero nos certames juninos, pretendo agora falar acerca dos concursos de miss voltados para mulheres cisgênero - denominados pelos quadrilheiros como concursos de miss mulher - e os concursos de Miss Gay ou Mix - destinados aos homens homossexuais e às pessoas com identidades 'trans' femininas. Para produzir um efeito comparativo, analisarei também os regulamentos dos concursos 
nacionais de Rainhas organizados pela CONFEBRAQ. Nesse caso, as rainhas nacionais equivalem às misses paraenses. Interessam-me tanto as rainhas que são mulheres cisgênero quanto as rainhas que são pessoas 'trans'.

De modo geral, há uma explícita oposição entre cisgeneridade e transgeneridade vinculada, respectivamente, aos regulamentos para concursos de misses ou rainhas que são mulheres cisgênero em contraste aos regulamentos destinados aos concursos de misses ou rainhas 'trans'. No caso do Pará, exponho a seguir o que diz o regulamento formulado pela FCP/Centur quanto à admissão de inscrições em diversas categorias juninas.
1.2. Compete à FUNDAÇÃO CULTURAL DO ESTADO DO PARÁ - FCP a Coordenação Geral do Concurso.
1.3. Serão admitidas inscrições nas seguintes categorias:
I - Coletivas:
(a) Quadrilha adulto (até 102 inscritos); (b) Quadrilha mirim (até 38 inscritos);
II - Individual:
(a) Miss Caipira adulto (feminino); (b) Miss Caipira mirim (feminino); (c) Miss Mulata Cheirosa adulto (feminino); (d) Miss Mulata Cheirosa mirim (feminino); (e) Miss Simpatia adulto (feminino); (f) Miss Simpatia mirim (feminino); (g) Miss Mix Caipira adulto (masculino); (h) Melhor Marcador adulto; (i) Melhor Marcador mirim; (j) Melhor Figurinista adulto; (k) Melhor Figurinista mirim; (I) Melhor Coreógrafo adulto; $(\mathrm{m})$ Melhor Coreógrafo mirim (FCP, 2016 [grifos meus]).

A disposição das categorias neste regulamento sugere uma divisão generificada dos quadrilheiros de modo a fixar certos brincantes em posições específicas quanto à condição cisgênero ou transgênero. Assim, é possível verificar que as categorias adultas de miss são todas classificadas como categorias do feminino, deixando óbvio que admitem apenas a inscrição de mulheres cisgênero. Em seguida, é possível observar que a categoria Miss Mix é designada como uma categoria do masculino, transparecendo que é destinada a pessoas que vivenciam experiências sociais com a condição transgênero. É curioso notar que a categoria 'marcador' não é classificada nem como masculina nem como feminina, embora não apareça no decorrer desse texto (e de outros regulamentos analisados) nenhuma designação dessa categoria flexionada no feminino, adotando também a nomenclatura 'marcadora'.

Com relação às misses, quero dizer que se, por um lado, há os concursos de Miss Mulher, que exigem a cisgeneridade como fator primordial para concorrer nas categorias que lhes são correlatas, por outro lado, há os concursos de Miss Mix, cuja determinação é a de que os sujeitos inscritos vivenciem alguma experiência social relativa à homossexualidade ou às identidades transgênero. Ainda que esses regulamentos reconheçam como um direito a livre expressão das identidades sexuais e de gênero, esse reconhecimento ocorre de modo essencializador, pautado na constituição da biologia dos corpos e não na experiência social e cultural dos sujeitos políticos. Mesmo que uma brincante transgênero esteja disputando o título de Miss Mix, que valoriza os atributos de 'feminilidade' das candidatas, ela deve ser considerada um 'homem' para cumprir com as determinações essencializadoras dos regulamentos.

É instigante perceber como, nos regulamentos oficiais destinados aos concursos de Miss Gay/Mix (emitidos pela FUMBEL e pela FCP/Centur), as categorias 'gay' e 'mix' aparecem sempre referidas no masculino e o termo usado para designar as pessoas que se inscrevem nessas categorias é 'candidato' (no masculino). Por outro lado, é revelador como, fora do âmbito dos concursos oficiais, os certames realizados nas 'periferias' de Belém se referem às pessoas 'trans' como candidatas (no feminino), tal como pude encontrar em todos os regulamentos dos concursos promovidos pelas quadrilhas Sedução Ranchista (bairro do Jurunas) e Garra Junina (distrito de Icoaraci). É notório que no concurso intitulado 'Soberanas do São João' (realizado pela Garra Junina) há apenas um regulamento para expor os critérios de avaliação tanto para as candidatas cisgênero quanto para as transgênero. Mais emblemático ainda é o fato de este regulamento estabelecer uma premiação distribuída da seguinte forma:

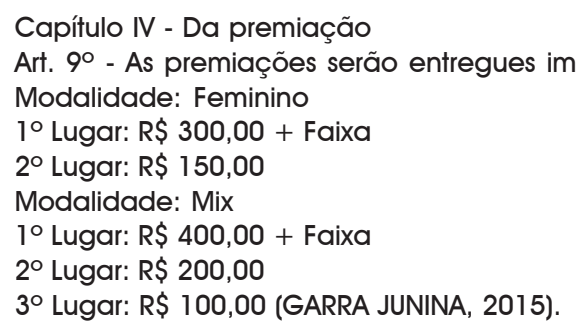

De acordo com os dados acima, além de a premiação para as candidatas mix ser maior, em termos de valores financeiros, do que a premiação destinada às candidatas da modalidade feminino, o número de candidatas contempladas com a premiação da categoria mix é também superior. Isso indica que, nas 'periferias' de Belém, os concursos juninos de dança e beleza voltados 
para a diversidade sexual e de gênero possuem uma proeminência que merece ser observada com atenção. Os próprios concursos de miss organizados pela quadrilha Sedução Ranchista no bairro do Jurunas são fortes indicadores desse protagonismo LGBT na quadra junina de Belém. Somente em 2014 a Sedução tomou a iniciativa para promover um concurso (denominado como Rainha do São João) voltado para mulheres cisgênero, ao passo que já realizava concursos voltados para gays e pessoas 'trans' há, pelo menos, 18 anos. ${ }^{7}$

Deve-se observar que, para além da grande relevância que os concursos mix possuem nas 'periferias' de Belém, o fato de os regulamentos tratarem essas candidatas sempre no feminino significa que os produtores culturais da 'periferia' estão mais habituados a lidar cotidianamente com pessoas que vivenciam identidades sexuais e de gênero diversas. Por outro lado, no âmbito da prefeitura de Belém (FUMBEL) e Governo do Pará (FCP/Centur), dois locus privilegiados da burocracia administrativa do Estado, essas candidatas são tratadas no masculino, ratificando o senso comum disseminado de que, embora possam até ter (em alguns estados brasileiros) os seus nomes sociais reconhecidos em instituições públicas, essas pessoas nunca são completamente consideradas como mulheres. Antes de ser submetida ao golpe parlamentar que a destituiu do poder, a presidente Dilma Rousseff assinou o decreto 8727/2016 para que todos os órgãos da administração pública federal utilizassem os nomes sociais de transexuais e travestis. Apesar de vários estados possuírem decretos que reconhecem o direito ao uso do nome social por parte de pessoas 'trans', essa matéria ainda não foi apreciada pelo conservador Poder Legislativo brasileiro e, portanto, não é um direito garantido constitucionalmente. Indico a leitura de Guilherme Almeida (2013) e Luiza Lima (2015) sobre a atuação do judiciário em processos de retificação de registro civil de pessoas transexuais.

Em âmbito nacional, pretendo problematizar alguns pontos dos regulamentos dos concursos de Rainhas (2015d e 2016b) e dos I e II Concursos Nacional de Rainha Junina da Diversidade (2015c; 2016c), todos eles promovidos pela CONFEBRAQ. Pelo fato de ser um concurso com abrangência nacional, as candidatas só poderiam se inscrever mediante indicação das respectivas entidades de quadrilhas juninas às quais estivessem filiadas. No caso do concurso de Rainhas Juninas (voltado para mulheres cisgênero), o regulamento estabelecia que

Art. $3^{\circ}$ - A candidata selecionada pela entidade deverá cumprir os seguintes pré-requisitos:

I - Ser do sexo feminino;

II - Ser brincante de um Grupo de Quadrilha Junina filiada à Entidade Estadual que for filiada à CONFEBRAQ;

III - Ter nacionalidade brasileira;

IV - Ter até a data do concurso 19/08/2016 a idade mínima de 16 anos, comprovados através de carteira de identidade ou certidão de nascimento originais;

Parágrafo único - No caso de gravidez, as candidatas deverão apresentar atestado médico, que autorize sua participação em eventos do tipo.

Art. $4^{\circ}$ - As informações contidas na ficha de inscrição serão de responsabilidade das candidatas. Em caso de informações inverídicas, a candidata poderá ser desclassificada do concurso (CONFEBRAQ, 2016c [grifos meus]).

Antes de analisar os critérios expostos no regulamento do V Concurso Nacional da Rainha Junina (citação anterior), pretendo colocá-los em contraste com os critérios do regulamento do I Concurso da Rainha Junina da Diversidade, conforme exposto a seguir:

Art. $3^{\circ}$ - Somente poderão participar do Concurso os candidatos que atenderem aos seguintes requisitos:

I - Ser do sexo masculino;

II - Ter nacionalidade brasileira;

III - Ser brincante ou membro de grupo ou quadrilha junina filiada à entidade estadual que for filiada à CONFEBRAQ;

IV - Ter até a data do Concurso a idade mínima de 18 anos, comprovados através de Carteira de Identidade ou Certidão de Nascimento.

Art. $4^{\circ}$ - Todas as informações contidas na ficha de inscrição serão de responsabilidade dos candidatos e de suas entidades. Em caso de informações comprovadamente inverídicas, os candidatos serão desclassificados do Concurso (CONFEBRAQ, 2015c [grifos meus]).

Colocados em contraponto, é possível notar como esses dois regulamentos entrelaçam marcadores sociais da diferença tais como gênero, sexualidade e geração. Nos concursos de Rainha Junina, a exigência recai sobre a condição cisgênero das candidatas. Nos concursos de

\footnotetext{
${ }^{7}$ A Sedução Ranchista é uma quadrilha junina vinculada à escola de samba Grêmio Recreativo Jurunense Rancho Não Posso me Amofiná (o Rancho). Oficialmente, a organização do Rancho e a quadrilha Sedução Ranchista passaram a contabilizar os concursos de Miss Gay/Mix a partir do ano 2000. No entanto, Sharize Ariell, uma conhecidíssima miss gay de Belém, foi campeã dos concursos do Rancho já na década de 1990. Portanto, a contagem oficial divulgada pelo Rancho não consiste no número real de certames já realizados, mas reflete o momento em que esses certames passaram a ser encarados como uma programação oficial dessa associação cultural.
} 
Rainha Junina da Diversidade, a experiência transgênero é requerida e é ressaltada pelo fato de o regulamento usar referências masculinas para se referir às possíveis pessoas inscritas nesses certames. Conforme tentei mostrar com exemplos anteriores, essa oposição entre cisgeneridade e transgeneridade está presente nos certames promovidos em âmbito local (Belém/FUMBEL) e estadual (Pará/FCP/Centur). Mas pretendo agora destacar um aspecto geracional contido nos regulamentos da CONFEBRAQ. ${ }^{8}$ Enquanto a idade mínima de 16 anos é requerida para as candidatas cisgênero, as candidatas transgênero precisam ter, minimamente, 18 anos para que se inscrevam nos certames. Esse item do regulamento visa resguardar os organizadores quanto a possíveis problemas judiciais que envolvam adolescentes cujas famílias venham a ter problemas quanto à expressão pública de suas identidades sexuais e de gênero.

É válido destacar que ambos os regulamentos da CONFEBRAQ (2016b e 2016c) são explícitos ao determinar que qualquer informação inverídica acarretará a desclassificação das candidatas. A partir dessa informação, quero trazer à tona uma situação que vivenciei em campo. Na noite do $\checkmark$ Concurso Nacional da Rainha Junina (realizado em Belém e promovido pela CONFEBRAQ), fui advertido de um boato sobre uma suposta mulher transexual concorrendo ao título nacional de Rainha Junina. Disseram-me que essa candidata só conseguiu ter sua inscrição deferida no certame porque já havia passado por um processo de transgenitalização.

Contudo, em diálogo com meus interlocutores em campo, soube que seria impossível que a inscrição dessa candidata fosse efetivada no concurso de rainhas da CONFEBRAQ caso ela tentasse usar uma carteira de Registro de Identificação Social. ${ }^{9}$ Portanto, a candidata só conseguiu fazer sua inscrição porque é mulher cisgênero, tendo em vista que esse critério é inegociável para o regulamento da CONFEBRAQ. Ocir Oliveira, envolvido com a produção desse concurso em específico, contou-me que a candidata era mulher cisgênero, pois, caso não fosse, as outras concorrentes ao título iriam denunciá-la a fim de eliminá-la da disputa. Ainda que fosse cisgênero, a suspeita sobre sua identidade de gênero causou certo alvoroço naquele contexto e, para mim, pode suscitar debates acerca da ampliação da categoria 'mulher' nos regulamentos desse tipo de certame. De todo modo, a existência do boato é emblemática para a reflexão acerca da perene e desagradável situação de desconfiança à qual as pessoas 'trans' são submetidas, sendo rotineiramente percebidas de modo hiperbólico, como Almeida (2013) assinalou. No fim das contas, o boato sobre a candidata era improcedente. Em 2017, acompanhei pelas redes sociais sua gravidez e o nascimento de sua filha, fato que sepultou definitivamente os boatos acerca de sua transexualidade.

Destaco o fato de os regulamentos dos concursos nacionais de Rainha Junina solicitarem às candidatas gestantes a comprovação, via atestado médico, de boas condições físicas para dançar sem prejudicar a gravidez. Obviamente, essa é uma medida de segurança em relação à saúde das possíveis gestantes. Entretanto, numa análise provocativa que proponho, a apresentação de atestado médico que faça referência à gravidez de uma candidata é também uma prova inquestionável de sua condição cisgênero. Do ponto de vista da comprovação biológica do sexo, o atestado médico referente à gestação poderia isentar as candidatas de apresentarem suas carteiras de identidade. Isso só não seria possível porque, a partir de outro ponto de vista, todo e qualquer sujeito precisa ser civilmente identificado em processos seletivos.

No entanto, é a carteira de identidade que possui maior status na hierarquia dos documentos que permitem acesso aos certames, pois ela retém todas as informações necessárias para a plena identificação civil dos sujeitos e, implicitamente, para a comprovação de suas respectivas condições de cisgeneridade ou transexualidade. Destaco ainda que, nos concursos de miss sob coordenação da FUMBEL, há um aspecto geracional significativo também passível de verificação a partir da carteira de identidade. De acordo com o regulamento do concurso de miss:

Art. $5^{\circ}$ - Estarão aptas a participarem dos Concursos de MISS CAIPIRA, MISS SIMPATIA e MORENA CHEIROSA as candidatas que, além de regularmente inscritas, representem Quadrilhas Juninas MIRIM ou ADULTA, devidamente inscritas no "Concurso de Quadrilhas Juninas 2014".

$\S 1^{\circ}$ - Na Categoria MIRIM somente serão admitidas candidatas com idade de 07 a 14 anos. $\S 2^{\circ}$ - Na Categoria ADULTA somente serão admitidas candidatas com idade de 13 a 30 anos (FUMBEL, 2014c [grifos meus]).

A delimitação da faixa etária até a idade máxima de 30 anos para disputar nas categorias adultas foi fator decisivo para que minha interlocutora, Clara Cardoso, fosse impedida de disputar (em 2014) o título de Miss Caipira pela quadrilha Arrastão Junino, grupo coreográfico do bairro da Cidade Velha. Até então, não havia restrição de idade nos certames dos anos anteriores. Interessante notar que, ao disputar o concurso da FCP/Centur neste mesmo ano, Clara pôde concorrer ao título tendo em vista que, ao contrário da FUMBEL, os regulamentos não estabeleciam um limite etário para as candidatas. Indaguei Ruth Botelho, técnica cultural da FUMBEL, sobre esse

${ }^{8}$ Esses aspectos geracionais também foram identificados nos regulamentos da FUMBEL e FCP/Centur, mas não vou reproduzi-los aqui para não incorrer em repetição.

` Documento válido como identificação civil e que reconhece o nome social de pessoas 'trans'. 
assunto. A gestora argumentou que a determinação de um limite de idade visava à promoção de uma renovação no quadro geral de misses da cidade, tendo em vista que muitas candidatas se repetem anualmente nos concursos e, em muitos casos, não conquistam os títulos almejados. Além desse argumento técnico, Ruth Botelho deixou entrever as concepções normativas de gênero com as quais opera, indicando que uma candidata ao título de miss deve ser jovem e magra, características que considera não condizentes com mulheres acima de 30 anos. A gestora sugere que as candidatas que queiram continuar dançando como miss na quadra junina de Belém devem procurar se inscrever em outra categoria: Miss Melhor ldade. Contudo, também fiz trabalho de campo no concurso de Miss Caipira da Melhor Idade em 2014 e consultei o regulamento que regia o certame (FUMBEL, 2014d). ${ }^{10}$ Segundo o documento, que está em conformidade com as definições da Lei 10.741/2003 (Estatuto do Idoso), o concurso de Miss Melhor ldade é destinado a pessoas com idade igual ou superior a 60 anos. Isso significa dizer que, na lógica imposta pela FUMBEL, as misses que completam a idade de 30 anos serão submetidas a uma longa exclusão da quadra junina de Belém até que atinjam a idade de 60 anos e possam disputar os títulos de Miss Melhor ldade.

Nesse regulamento, há um capítulo revelador que diz respeito aos impedimentos relativos às Misses da Melhor ldade, conforme disposto a seguir:

Capítulo IV - Dos impedimentos

Art. $9^{\circ}$ - É expressamente proibido às candidatas participantes do concurso:

a) Ter idade inferior a 60 anos;

b) Estarem ausentes após a $3^{a}$ chamada;

c) Pertencerem ao sexo masculino (FUMBEL, 2014d [grifos meus]).

Estabelecendo o limite inicial de idade de acordo com o Estatuto do Idoso, o regulamento traz o impedimento da participação de candidatas com identidades transgênero, enfatizando que só são permitidas inscrições de candidatas cisgênero. Isso indica que a FUMBEL reconhece a existência da possibilidade de que homossexuais e pessoas 'trans' com idade mais avançada queiram se inscrever nos certames. Esse fato também evidencia que, diante dessa constatação, a FUMBEL ainda não pensou em criar um concurso específico voltado para aqueles integrantes da população LGBT que se encaixem na categoria social 'idoso'. Estudos recentes da antropologia brasileira vêm tratando acerca da temática do envelhecimento das populações LGBT. Recomendo a leitura dos textos de Mônica Siqueira (2009) e Carlos Eduardo Henning (2016).

Novamente, a carteira de identidade, para além de suas finalidades óbvias como documento de identificação civil, desempenha a função de atestar a passagem do tempo na vida das candidatas, assegurando se podem ou não estarem inscritas no referido concurso. Da mesma forma, é carteira de identidade que atesta a condição cisgênero dessas candidatas idosas. Em todos os exemplos que mobilizei até aqui, seja nos concursos voltados para pessoas cisgênero ou transgênero, seja nos concursos de quadrilha ou de miss, busquei problematizar a carteira de identidade para além da soberania de seu papel como documento civil de identificação, requisito necessário para o recebimento da apresentação dos sujeitos em processos de seleção como esses que venho analisando. Mais do que identificar pessoas, individualizando-as nas categorias nas quais concorrem, a carteira de identidade é também uma importante aliada para trazer à tona uma suposta verdade ontológica dos sujeitos, expondo seus respectivos sexos biológicos como indicativos de suas condições cisgênero ou transgênero. Embora a carteira de identidade não possua um campo denominado como 'sexo', tal qual a certidão de nascimento possui, ainda assim se constitui como um documento que fornece pistas relevantes para a aferição da cisgeneridade dos sujeitos. Para aquelas pessoas que não conseguiram acessar o direito à requalificação civil, mostrar a carteira de identidade, com seus respectivos nomes civis atribuídos na certidão de nascimento, pode configurar-se como uma autodenúncia quanto à sua condição transgênero.

Antes de continuar problematizando exigência da carteira de identidade nos concursos promovidos pelos poderes públicos, é válido lembrar que os certames organizados pelo Estado ou associações e federações de quadrilheiros espalhados por todo o Brasil mantêm uma relação dialógica com os concursos 'não oficiais' realizados nas 'periferias' das grandes e pequenas cidades onde o movimento junino se faz presente. Isso significa que há um campo de influências mútuas no qual o Estado e as associações/federações quadrilheiras exercem influência sobre os produtores culturais das 'periferias' e seus modos de organizar os certames e, por outro lado, a experiência nesses concursos 'periféricos' traz demandas importantes que são ouvidas pelo Estado e pelas associações/federações juninas. Nesses termos, as festas juninas são uma tradição visivelmente inacabada, que se constrói gradualmente, de modo a torná-las atrativas para todos os sujeitos e setores sociais envolvidos nessa dinâmica de produção da cultura popular.

${ }^{10} \mathrm{O}$ trabalho de campo no concurso de Miss Caipira da Melhor Idade foi realizado apenas para produzir uma observação comparativa com relação aos outros concursos de Miss. No entanto, essa categoria de miss não constituiu objeto de discussão nesta pesquisa. 
Dito isso, volto ao meu ponto sobre a exigência da carteira de identidade. Embora haja um campo de influências mútuas entre os dois tipos de concursos, que transparece diferenças, semelhanças e processos de mudança em curso, pretendo ressaltar que há uma diferença relevante entre os concursos realizados nas 'periferias' de Belém e os certames promovidos pelos poderes públicos e/ou associações/federações estaduais juninas. A consulta aos regulamentos demonstrou que a carteira de identidade não é exigida nos certames da 'periferia', ao passo que é um documento de identificação imprescindível nos concursos do Estado e das associações/federações juninas. Esse é um dado importante a ser problematizado. Nas diversas edições dos concursos de miss das 'periferias' em que tive a oportunidade de fazer trabalho de campo, não houve, em nenhum deles, a exigência da carteira de identidade das candidatas. "Isso é válido tanto para os concursos de Miss Mulher ou Miss Gay/Mix. Esse fator é significativo do nível de comunicabilidade e controle social que há nas 'periferias' por parte dos próprios sujeitos sociais que as habitam, evidenciando que as identidades sociais, sexuais e de gênero dos agentes que movimentam a cena junina nesses bairros são amplamente conhecidas de todas as pessoas que organizam ou frequentam esses certames. Tal conhecimento prévio consiste em uma certeza sobre a 'verdade' social, sexual e de gênero dos sujeitos, dispensando a exigência da carteira de identidade como um documento que também comprova a condição cisgênero ou transgênero das candidatas.

Por outro lado, do ponto de vista dos concursos promovidos pelo Estado ou pelas associações/ federações quadrilheiras, parece haver uma compreensão de que "os documentos são fornecidos por órgãos públicos apenas para aqueles que preenchem determinados requisitos estipulados pela lei. Eles cumprem, portanto, a função de distinguir o cidadão do marginal" (Mariza PEIRANO, 2006, p. 123 [grifo da autora]). Sugiro, portanto, que, do ponto de vista desses concursos juninos organizados pelo Estado, a exigência de documentos de identificação civil seja também responsável por imprimir certa legitimidade ao trabalho artístico desenvolvido pelos sujeitos das 'periferias'. No que diz respeito à população 'trans', para além de expor negativamente identidades 'masculinas' que pretendem ser apagadas pelos sujeitos, a exigência da carteira de identidade, por outro lado, faz com que a diversidade sexual e de gênero saia, ao menos temporariamente, de uma condição cotidiana de marginalidade (ou do campo semântico do conceito de desvio moral) a partir de uma relação formal com o Estado.

\section{Das formas implícitas de dizer}

No que dizem e no que escondem, os regulamentos falam acerca de processos classificatórios mais amplos, pois os concursos juninos operam com categorias classificatórias nem sempre explícitas, mas passíveis de observação etnográfica. Os sujeitos são alocados em determinados grupos que dizem respeito às identidades sociais que possuem, que reivindicam ou que aparentam ter. Nessa configuração, os quadrilheiros são percebidos a partir de suas condições sociais como pessoas cis ou transgênero, hetero ou homossexuais, 'brancas' ou 'negras' e 'mulatas' ou 'morenas'. Ao adotarem esses processos classificatórios, os concursos juninos suscitam a reflexão sobre o fato de que "todo sistema classificatório não apenas divide o mundo em unidades semânticas que já têm, elas mesmas, efeito pragmático, mas também 'declara' a maneira como essas unidades devem ser manipuladas e avaliadas" (Vincent CRAPANZANO, 2001, p. 444). Um fator que une todos esses quadrilheiros, estratificados pelos processos classificatórios dos concursos juninos, é a condição de serem sujeitos 'periféricos'. Mais precisamente, trata-se de sujeitos que habitam periferias sexuais, raciais e de gênero, entrecortadas por experiências de classe social, que os colocam numa condição partilhada de subalternidade.

Percorrer os textos dos regulamentos, contrapondo-os aos discursos e práticas dos gestores culturais da FUMBEL e da FCP/Centur, permite perceber de modo crítico a ação estatal na delimitação das fronteiras que circunscrevem a cultura popular. Essa observação obstinada também possibilita enxergar as reações dos quadrilheiros frente às regras (im)postas pelo Estado, pressionando-o a contemplar as demandas colocadas pelas quadrilhas e seus brincantes. Embora haja uma incontestável assimetria de forças entre o Estado e os quadrilheiros, é possível vislumbrar uma relação em que o Estado produz a cultura popular e, por sua vez, a cultura popular reconstrói o Estado.

Constituído internamente por forças plurais e conflitantes, o Estado seria definido exatamente por seu caráter não coeso, não 'real' e essencialmente inacabado, um estado-ideia, como Philip Abrams (1988) o designa. É a relação dialógica com diversos setores do próprio Estado, através da qual os sujeitos de direitos negociam com essa entidade abstrata e polimorfa, que proporciona (talvez) alcançar uma interferência efetiva no conjunto de ações e na estrutura institucional do Estado, denominados por Abrams (1988) como o estado-sistema. Nessa perspectiva, o Estado não pode ser encarado como um objeto materialmente concreto de estudo. Segundo Abrams (1988), 0 Estado não é uma concreta estrutura fundamental oculta atrás da máscara das práticas políticas. Em direção oposta, o Estado é uma abstração, uma espécie de máscara ilusória, forjada pela

"Cito como exemplo de concursos que acompanhei nas 'periferias' de Belém os certames do Rancho e da Tia Wal (no bairro do Jurunas), Melhor do Bairro (no Benguí), Clube dos Comerciários (no município de Ananindeua), dentre outros. 
realidade dos processos e práticas políticas (ABRAMS, 1988, p. 82). O Estado se constrói de modo processual, cotidiano e performático a partir do que Antônio Carlos de Souza Lima (2012) denomina como o fazer Estado, isto é, uma prática

constante, resultando em formas que não são definitivas, em processos de objetificação e subjetivação que operam construindo e desconstruindo realidades no plano da vida diária, adquirindo a dimensão de automatismos, oriundos ou não de imposições emanadas de um corpo administrativo apoiado em leis e normas (p. 561).

Ao analisar os regulamentos que orientam os concursos juninos, compartilho da ideia de que

levar a sério os documentos como peças etnográficas implica tomá-los como construtores da realidade tanto por aquilo que produzem na situação na qual fazem parte - como fabricam um "processo" como sequência de atos no tempo, ocorrendo em condições específicas e com múltiplos e desiguais atores e autores - quanto por aquilo que conscientemente sedimentam (Adriana VIANNA, 2014, p. 47).

Ao me debruçar sobre tais regulamentos, busquei percebê-los como "mais do que instrumentos de registro usados por burocratas e apreendê-los em termos de como eles constituem, hierarquizam, separam e conectam pessoas" (Laura LOWENKRON; Letícia FERREIRA, 2014, p. 83). No caso em questão, tentei problematizar como os concursos juninos têm optado por gerir 0 protagonismo LGBT que se tradicionalizou nas festas juninas de Belém (e do Brasil). Para além do que está dito textualmente nos regulamentos, é preciso atentar para as formas implícitas de dizer, que estão presentes tanto nas entrelinhas das regras que regem os certames quanto nos discursos e práticas dos gestores culturais que elaboram políticas de promoção e fomento das culturas populares. Todo esse aparato discursivo acaba por moldar as práticas quadrilheiras, regulando corpos, sujeitos e, sobretudo, performances.

\section{Referências}

ABRAMS, Philip. "Notes on the Difficulty of Studying the State". Journal of Historical Sociology, v. 01, n. 1, p. 58-89, mar. 1988.

ALMEIDA, Guilherme. "A propósito da discussão de feminilidades trans: notas sobre invisibilização, cidadania, corpo e processo transexualizador". In: SILVA, Daniele Andrade; HERNANDÉZ, Jimena de Garay.; SILVA JUNIOR, Aureliano Lopes da; UZIEL, Anna Paula (Orgs.). Feminilidades: corpos e sexualidades em debate. Rio de Janeiro: EDUERJ, 2013. p. 107-118.

BENEDETTI, Marcos. Toda feita: o corpo e o gênero das travestis. Rio de Janeiro: Garamond, 2005.

BENTO, Berenice. A reinvenção do corpo: sexualidade e gênero na experiência transexual. Rio de Janeiro: Garamond, 2006.

BENTO, Berenice. "A diferença que faz a diferença: corpo e subjetividade na transexualidade". Bagoas, n. 04, p. 95-112, 2009.

BENTO, Berenice. "Sexualidade e experiências trans: do hospital à alcova". Ciência e Saúde Coletiva, v. 17, n. 10, p. 2655-2664, 2012.

BENTO, Berenice; PELÚCIO, Larissa. "Despatologização do gênero: a politização das identidades abjetas". Revista Estudos Feministas, v. 20, n. 2, p. 569-581, 2012.

BURKE, Peter. Cultura popular na Idade Moderna: Europa 1500-1800. São Paulo: Companhia das Letras, 2010 [1978].

BUTLER, Judith. Problemas de gênero: feminismo e subversão da identidade. Rio de Janeiro: Civilização Brasileira, 2010.

BUTLER, Judith. "Corpos que pesam: sobre os limites discursivos do 'sexo'”. In: LOURO, Guacira (Org.) O corpo educado: pedagogias da sexualidade. Belo Horizonte: Autêntica, 2016. p. 151-172.

CHIANCA, Luciana. São João na cidade: ensaios e improvisos sobre a festa junina. João Pessoa: EDUFPB, 2013.

CLIFFORD, James. A experiência etnográfica: antropologia e literatura no século XX. Rio de Janeiro: EDUFRJ, 2011 [1994].

CLIFFORD, James; MARCUS, George (Orgs.). A escrita da cultura: poética e política da etnografia. Rio de Janeiro: EDUERJ/Papéis Selvagens, 2017 [1986]. 
CONFEBRAQ. I Concurso Nacional de Casais de Noivos Juninos, 2015b.

CONFEBRAQ. I Concurso Nacional de Rainha Junina da Diversidade, 2015c.

CONFEBRAQ. Regulamento do IV Concurso Nacional de Rainhas Juninas, 2015d.

CONFEBRAQ. Regulamento do XII Concurso Nacional de Quadrilhas Juninas, 2016 a.

CONFEBRAQ. Regulamento do V Concurso Nacional da Rainha Junina, 2016b.

CONFEBRAQ. Regulamento do II Concurso Nacional de Rainha Junina da Diversidade, $2016 \mathrm{c}$.

CRAPANZANO, Vincent. "Estilos de interpretação e a retórica de categorias sociais". In: MAGGIE, Yvonne; REZENDE, Claudia (Orgs.). Raça como retórica: a construção da diferença. Rio de Janeiro: Civilização Brasileira, 2001. p. 441-458.

CUNHA, Manuela Carneiro da. "'Cultura' e cultura: conhecimentos tradicionais e direitos intelectuais". In: CUNHA, Manuela Carneiro da. Cultura com aspas e outros ensaios. São Paulo: Cosac Naify, 2009. p. 311-373.

DI DEUS, Eduardo. "Quadrilhas juninas como um movimento de juventude em Rio Branco, Acre". Sociedade e Cultura, v. 17, n. 1, p. 75-85, 2014.

FCP. Regulamento Geral do Arraial de todos os santos/2016. XIII Concurso Estadual de Quadrilhas Juninas. Categorias: adultas, mirins e miss, 2016.

FUMBEL. Regulamento Geral do Concurso de Quadrilhas Juninas Mirins e Adultas de Belém, $2014 a$.

FUMBEL. Regulamento Geral do Concurso de Misses Juninas Adultas e Mirins, 2014b.

FUMBEL. Manual de Jurados, $2014 \mathrm{c}$.

FUMBEL. Regulamento do Concurso de Miss Caipira da Melhor Idade, 2014d.

GARRA JUNINA. Regulamento do Concurso Soberanas do São João, 2015.

GOMES, Elielton. Adeus Maio! Salve Junho!: narrativas e representações dos festejos juninos em Belém do Pará nos anos de 1950. 2016. Dissertação (Mestrado em História Social da Amazônia) Programa de Pós-Graduação em História Social da Amazônia. Faculdade de História da UFPA, Universidade Federal do Pará, Belém, PA, Brasil.

HENNING, Carlos Eduardo. "Is old age always already heterossexual (and cisgender)? The LGBT Gerontology and the formation of the 'LGBT elders'”. Vibrant, v. 13, n. 1, p. 132-154, 2016.

HOBSBAWM, Eric; RANGER, Terence. A invenção das tradições. Rio de Janeiro: Paz e Terra, 2012 [1983].

KULICK, Don. Travesti: prostituição, sexo, gênero e cultura no Brasil. Rio de Janeiro: Fiocruz, 2008.

KUPER, Adam. Cultura, a visão dos antropólogos. Bauru: EDUSC, 2002.

LEAL, Eleonora. Contando o tempo: a evolução coreográfica das quadrilhas juninas em Belém do Pará. 2004. Dissertação (Mestrado em Artes Cênicas) - Programa de Pós-Graduação em Artes Cênicas, Escola de Dança e Teatro da UFBA, Universidade Federal da Bahia, Salvador, BA, Brasil.

LEITE JR., Jorge. Nossos corpos também mudam: a invenção das categorias "travesti" e "transexual" no discurso científico. São Paulo: Annablume, 2011.

LIMA, Elizabeth. A festa de São João nos discursos bíblico e folclórico. Campina Grande: EDUFCG, 2010.

LIMA, Luiza. A 'verdade' produzida nos autos: uma análise sobre decisões judiciais sobre retificação de registro civil de pessoas transexuais em Tribunais brasileiros. 2015. Dissertação (Mestrado em Antropologia Social) - Programa de Pós-Graduação em Antropologia Social, Faculdade de Filosofia, Letras e Ciências Humanas da USP, Universidade de São Paulo, São Paulo, SP, Brasil.

LOWENKRON, Laura; FERREIRA, Letícia. "Anthropological perspectives on documents: ethnographic dialogues on the trail of police papers". Vibrant, v. 11, n. 2, p. 76-112, 2014. 
MENEZES NETO, Hugo. "Música e festa na perspectiva das quadrilhas juninas de Recife". Anthropológicas, v. 26, n. 1, p. 103-133, 2015.

NASCIMENTO, Suely. “Será que ele é?”. O Liberal, Caderno Troppo, 10 jun., Belém, 2001, p. 16-18.

NÓBREGA, Zulmira. A festa do maior São João do mundo: dimensões culturais da festa junina na cidade de Campina Grande. 2010. Tese (Doutorado em Cultura e Sociedade) - Programa Multidisciplinar de Pós-Graduação em Cultura e Sociedade, Faculdade de Comunicação da UFBA, Universidade Federal da Bahia, Salvador, BA, Brasil.

NOLETO, Rafael da Silva. "'Quero ficar no teu corpo feito tatuagem': cantoras brasileiras, fãs homossexuais e performatividades". In: NOGUEIRA, Isabel Porto; FONSECA, Susan Campos (Orgs.). Estudos de gênero, corpo e música: abordagens metodológicas. Goiânia/Porto Alegre: ANPPOM, 2013. p. 203-232.

NOLETO, Rafael da Silva. "'Brilham estrelas de São João!': notas sobre os concursos de 'Miss Caipira Gay' e 'Miss Caipira Mix' em Belém (PA)". Sexualidad, salud y sociedad - Revista Latino-Americana, n. 18, p. 74-110, 2014. DOI 10.1590/1984-6487.sess.2014.18.06.a. Acesso em 26/05/2019.

NOLETO, Rafael da Silva. Brilham estrelas de São João: gênero, raça e sexualidade em performance nas festas juninas de Belém - PA. 2016. Doutorado (Programa de Pós-Graduação em Antropologia Social) - Faculdade de Filosofia, Letras e Ciências Humanas da Universidade de São Paulo, São Paulo, SP, Brasil.

NOLETO, Rafael da Silva. "Casamento em performance, parentesco em questão: gênero e sexualidade no São João de Belém, Pará". Cadernos Pagu, n. 51, e175120, 2017. DOI 10.1590/ 18094449201700510020. Acesso em 26/05/2019.

NOLETO, Rafael da Silva. "Cor de jambo e outros matizes amazônicos: sobre a abolição da mulata e o advento da morena cheirosa nas festas juninas de Belém". Mana, v. 24, n. 2, p. 132-173, 2018 a. DOI 10.1590/1678-49442018v24n2p132. Acesso em 26/05/2019.

NOLETO, Rafael da Silva. "Limites do gênero, fronteiras da sexualidade: heterossexualidade e cisgeneridade coreográfica na quadra junina de Belém”. In: SAGGESE, Gustavo; MARINI, Marisol; LORENZO, Rocio; SIMÕES, Julio; CANCELA, Cristina (Orgs.). Marcadores sociais da diferença: gênero, sexualidade, raça e classe em perspectiva antropológica. São Paulo: Terceiro Nome/Gramma, 2018b. p. 287-305.

PEIRANO, Mariza. “'Sem lenço, sem documento': cidadania no Brasil”. In: PEIRANO, Mariza. A teoria vivida e outros ensaios de antropologia. Rio de Janeiro: Jorge Zahar Editor, 2006. p. 121-134.

RICH, Adrienne. "Heterossexualidade compulsória e existência lésbica”. Bagoas, v. 5, p. 17-44, 2010.

SIQUEIRA, Mônica Soares. Arrasando horrores! Uma etnografia das memórias, formas de sociabilidades e itinerários urbanos de travestis das antigas. 2009. Tese (Doutorado em Antropologia Social) - Programa de Pós-Graduação em Antropologia Social, Faculdade de Ciências Sociais da UFSC, Universidade Federal de Florianópolis, Florianópolis, SC, Brasil.

SOUZA LIMA, Antônio Carlos de. "Apresentação". Revista de Antropologia, v. 55, n. 2, p. 559-564, 2012. (Dossiê Fazendo Estado)

VENCATO, Anna Paula. Fervendo com as drags: corporalidade e perfomances de drag queens em territórios gays da llha de Santa Catarina. 2002. Dissertação (Mestrado em Antropologia Social) - Programa de Pós-Graduação em Antropologia Social, Faculdade de Ciências Sociais da UFSC, Universidade Federal de Santa Catarina, Florianópolis, SC, Brasil.

VENCATO, Anna Paula. "Confusões e Estereótipos: o ocultamento de diferenças na ênfase de semelhanças entre transgêneros". Cadernos AEL, v. 10, n. 18/19, p. 185-218, 2003.

VENCATO, Anna Paula. Sapos e princesas: prazer e segredo entre praticantes de crossdressing no Brasil. São Paulo: Annablume, 2013.

VIANNA, Adriana. "Ełnografando documentos: uma antropóloga em meio a processos judiciais". In: CASTILHO, Sérgio; LIMA, Antônio Carlos de Souza; TEIXEIRA, Carla (Orgs.). Antropologia das práticas de poder: reflexões etnográficas entre burocratas, elites e corporações. Rio de Janeiro: Contra Capa, 2014. p. 43-70. 
WAGNER, Roy. A invenção da cultura. São Paulo: Cosac Naify, 2012 [1975].

Rafael da Silva Noleto (rafaeldasilvanoleto@gmail.com) é Professor Adjunto da Universidade Federal de Pelotas. Docente no Programa de Pós-Graduação em Antropologia (PPGAnt/ UFPel) e no Bacharelado em Ciências Musicais. Antropólogo, cantor e compositor. Tem interesse em Etno/Musicologia, Antropologia da Performance, Estudos de Gênero e Sexualidade, Relações Raciais e Teoria Antropológica.

\section{COMO CITAR ESSE ARTIGO DE ACORDO COM AS NORMAS DA REVISTA}

NOLETO, Rafael da Silva. "Regulamentos da cultura: diversidade sexual e de gênero nos concursos juninos de Belém". Revista Estudos Feministas, Florianópolis, v. 28, n. 1, e56099, 2020.

\section{CONTRIBUIÇÃO DE AUTORIA}

Rafael da Silva Noleto - Autoria integral do texto, incluindo a execução do trabalho de campo, a produção e análise dos dados e também a redação final do artigo.

\section{FINANCIAMENTO}

O presente trabalho foi realizado com apoio da Coordenação de Aperfeiçoamento de Pessoal de Nível Superior - Brasil (CAPES) - Código de Financiamento 001. A pesquisa foi financiada pela CAPES entre 2013 e 2015. (Obs.: Após 2015 abdiquei da bolsa de financiamento por ter sido aprovado em concurso público para atuar como professor do Magistério Superior).

\section{CONSENTIMENTO DE USO DE IMAGEM}

Não se aplica.

APROVAÇÃO DE COMITÊ DE ÉTICA EM PESQUISA

Não se aplica.

CONFLITO DE INTERESSES

Não se aplica.

LICENÇA DE USO

Este artigo está licenciado sob a Licença Creative Commons CC-BY Internacional. Com essa licença você pode compartilhar, adaptar, criar para qualquer fim, desde que atribua a autoria da obra.

\section{HISTÓRICO}

Recebido em 28/03/2018

Reapresentado em 21/06/2019

Aprovado em 01/08/2019 